\title{
Ergonomic Evaluation of Manually Operated Two Row Paper Pot Onion Transplanter
}

\author{
M. Suwathiga ${ }^{1 *}$, S. Thambidurai ${ }^{1}$, S. S. Sivakumar ${ }^{1}$ and M. Dhandapani ${ }^{2}$
}

${ }^{1}$ Dept. of Farm Machinery and Power Engineering, ${ }^{2}$ Dept. of Basic Engineering and applied Sciences Agricultural Engineering College and Research Institute, Tamil Nadu Agricultural University, Kumulur, Trichy, India

*Corresponding author

\section{A B S T R A C T}

Keywords

Paper pot transplanter, Ergonomics, Labour, Dimension of human body, Heart rate, drudgery, Energy expenditure rate

Article Info

Accepted: 20 October 2020 Available Online: 10 November 2020
The world production of vegetables, India is the second largest producer next to china. In India, there is no mechanization available for onion transplanting. The transplanting of onion seedlings mainly depends on farm workers. So, manually operated two row paper pot onion transplanter was developed. In agricultural mechanization, the major role of ergonomics is to increase the efficiency of the operation. The study was conducted to evaluate the manually operated two row paper pot onion transplanter and compared with conventional method of transplanting. It was found that the maximum heart rate, energy expenditure rate, oxygen consumption rate and work pulse value of farm workers were 118 beat $\mathrm{min}^{-1}, 9.8 \mathrm{KJ} \mathrm{min}-1,0.66 \mathrm{~L} / \mathrm{min}$ and 32 beats $\mathrm{min}^{-1}$ with the workload of moderate in two row paper pot onion transplanter and the maximum heart rate, oxygen consumption rate and energy expenditure rate of farm workers were 135 beats $\min ^{-1}, 12.6 \mathrm{KJ} \mathrm{min}{ }^{-1}, 0.859 \mathrm{~L} / \mathrm{min}$ and 50.5 beats $\mathrm{min}^{-1}$ with the work load of heavy in conventional method. The overall discomfort rate and musculo-skeletal problem is less in transplanter compared with conventional methods.

\section{Introduction}

Onion (Allium cepa L.) is an important vegetable that is used daily in a variety of ways. Onion demand is high worldwide. The total onion production in the world is 93.2226 million tonnes under an area of 4.96 million ha. India produces 19.2 million tonnes of onion from a cultivation area of 1.2 million ha, which is $19.9 \%$ of global production. Tamil Nadu produces 10.62 million tonnes of onion from a cultivation area of 28.36 thousand ha (Horticultural Statistics at a Glance, 2018).

Onion crop is raised by various methods such as direct seed sowing, planting bulbs in the field and raising nursery seedlings with subsequent transplanting in the field. In India, the most common method is transplanting because of high yield and better quality produce. However, transplanting of onion 
seedlings is done manually in all onion growing regions in India because of the nonavailability of suitable machines. But manual transplanting is more time consuming and labor-intensive than mechanical transplanting as the women workers have to work in bending posture. Labor shortage during peak season causes delays in transplanting, leading to a drastic reduction in yields (Chaudhari et al., 2001). As the demand for mechanization of onion production has increased in India due to the shortage of labor, an attempt has been made to develop a manually operated tworow paper pot onion transplanter that is structurally simple, functionally accurate, and economically feasible.

Ergonomics is the study of human abilities and characteristics which affect the design of equipment, system, and jobs. The suitability of equipment for farm women can better be judged using ergonomic studies, which cover all aspects that deal with anthropometry, assessment of workload, working environment, safety features, and mechanisms to optimize human-machine environment systems. This helps in increasing working efficiency with reduced drudgery by fitting to the capabilities and limits of human operators. The overall performance of a transplanter mainly depends on both constructional features and operation (Gite et al., 1997).

Many manually operated equipment like weeder, seeder, transplanter etc. Which are similar to developed transplanter were ergonomically evaluated by various researchers.

Tiwari and Gite (1998) estimated the heart rate, oxygen consumption rate and energy expenditure rate during weeding operation by using a power tiller. Singh S P, (2010) carried out a study on ergonomic evaluation of manually operated cono weeder with farm and the heart rate, work pulse rate and oxygen consumption rate was observed. Vyavahare et al., (2012) reported the review based on to produce the anthropometric and strength data of agricultural farm workers for designing farm equipment and to evaluate the ergonomics aspects of farm equipment. The main reason to evaluate the ergonomic and optimizations of farm equipment are to reduce the musculoskeletal disorder and to prevent injuries to farm workers while using farm equipment. Tripathi et al., (2016) conducted a study on ergonomic evaluation of vegetable production by hand operated salping transplanter and traditional method of transplanting. They measured heart rate, energy expenditure rate, muskulo-skeletal problem and posture discomfort rate and also compared with traditional method. Pradhan et al., (2014) conducted an experiment to calculate the heart rate, oxygen consumption and relative cost of workload in different paddy transplanting operations. To calculate the heart rate, energy expenditure and oxygen consumption rate, Yadav et al., (2007) investigated the ergonomic evaluation of a six row paddy transplanter which is manually operated. Vinay kumar et al., (2018) conducted an experiment on ergonomic evaluation of manually operated single row vegetable transplanter for different crops like brinjal, chilli, and tomato in different sites to work out heart rate and energy expenditure rate and compared with traditional method of transplanting. Amita Gautam et al., (2020) conducted an experiment on ergonomic evaluation of farm women for ambika paddy weeder and hand weeding, harvesting by serrated sickle and traditional sickle and threshing by paddy thresher and hand beating and also for winnowing operation to work out the heart rate, oxygen consumption rate and energy expenditure rate.

\section{Materials and Methods}

The study was done in agricultural engineering college and research institute. Based on the extensive review of several 
research papers, the ergonomic parameters selected. The selected ergonomic parameters are energy expenditure rate, work pulse rate, workload, overall discomfort rate and musculoskeletal problems.

The study was conducted to estimate the heart rate, energy expenditure rate, oxygen consumption rate, work pulse rate, work load, overall discomfort rate and musculo-skeletal problems in two row paper pot onion transplanter and compared with conventional method of onion transplanting.

\section{Selection of workers}

The 10 nos. of farm workers with good health and age between 25 - 35 years were selected. At an age group of $25-35$ years humans have maximum strength (Grandjean, 1982., Gite and Singh, 1997). Therefore, farm workers between the age group of $25-35$ years were selected. The Physiological characteristics of selected workers is given in Table 1.

\section{Growing of seedlings}

Seedlings were grown in a paper pot and also raised under a shade net. Commercially available mediums were used such as soil and soil + vermicompost + FYM (1:1:1). Water was sprinkled every day. $15 \mathrm{~cm}$ height and $0.8 \mathrm{~cm}$ neck diameter are suitable for onion transplanting. It is achieved in $6-10$ weeks depending on soil condition. Conventionally, the farmers were selected for the 30 days old plug seedlings for transplanting practices.

\section{Field preparation}

As per agronomic requirement the field was prepared for paper pot transplanting. By using cultivator and rotavator the field was prepared until soil tilth fine. The plot size was $20 \times 10 \mathrm{~m}$.

\section{Transplanting of onion seedlings}

The onion transplanter was designed with simple construction parts, low cost and more efficient in transplanting the onions. The CAD diagram is shown in fig 1 . The main functions of two row paper pot onion transplanter includes,

To open the furrow,

To convey the seedling due to gravity force and

Cover the seedling by using furrow closer.

The functional components are handle, tray, tray holder, paper pot conveyor body, furrow opener, ramp, furrow closer and friction wheel. The handle was designed based on ergonomically. The $5^{\text {th }}$ percentile value of elbow height for farm workers was $896 \mathrm{~mm}$ and the $95^{\text {th }}$ percentile value of elbow height for male workers was $1098 \mathrm{~mm}$ considered to design a handle. Handle height of the developed transplanter should be adjustable between $0.90-1.10 \mathrm{~m}$. Onion seedlings were transplanted by manually operated two row paper pot onion transplanter and also conventional method. Table 2 shows the specification of the developed transplanter.

\section{Ergonomic evaluation}

The transplanter was loaded with seedling trays and kept ready for the operation. The farm workers were asked to take sufficient rest before the start of operation. Ergonomic evaluation was conducted using both a developed transplanter and conventional method of onion seedlings shown in figure 2 and 3.

\section{Heart rate (beats min $^{-1}$ )}

The subject's heart rate was measured before and during operation using a polar heart rate wrist watch. The farm workers were asked to 
take sufficient rest before operation and after 30 minutes of work by transplanter and conventional method of transplanting, the heart rate was recorded.

\section{Energy expenditure rate ( $\left.\mathrm{KJ} \mathrm{min}^{-1}\right)$}

The Energy expenditure rate was calculated from heart rate, the Varghese (1994) proposed an equation. It is given below:

$\operatorname{EER}\left(\mathrm{KJ} \min ^{-1}\right)=0.159 \times \mathrm{HR}\left(\right.$ beats $\left.\min ^{-1}\right)-$ 8.72

\section{Oxygen consumption rate (OCR)}

OCR was determined by utilizing the formula derived by Singh et al., 2008. It is denoted by $\mathrm{L} \min ^{-1}$.

$$
\mathrm{OCR}(\mathrm{L} / \mathrm{min})=0.0114 \times \mathrm{HR}-0.68
$$

\section{Work pulse value}

Work pulse value was calculated by subtracting the mean heart rate during work with the mean heart rate during rest (Singh S.P, 2012). The calculated values of work pulse were compared with acceptable work pulse value of 40 beats $\mathrm{min}^{-1}$ as the limit of continuous performance (Brundke, 1984).

\section{Work load}

The workload was classified on the basis of average heart rate and average energy expenditure rate during transplanting operation. The workload was categorized as per the following classification of workload (Table 3) in different occupations proposed by Varghese et al., (1994).

\section{Musculo-skeletal problem (MSP)}

Musculoskeletal problems and posture were taken by asking the farm labours as to where they felt pain in their body after transplanting with onion transplanter and conventional method.

\section{Overall discomfort rate (ODR)}

ODR was measured by using visual analogue scale. It was divided into 10 equal parts (0 no discomfort, 10 - extreme discomfort). This scale was developed by Corlet and Bishop (1976). The length of scale is $70 \mathrm{~cm}$ (Fig. 4.). The overall discomfort rate was indicated by using movable pointers. After transplanting of seedlings by every farm labourers were called to mention their ODR on the scale.

\section{Results and Discussion}

\section{Ergonomics evaluation of developed transplanter}

\section{Energy expenditure rate}

Energy expenditure rate was calculated on the basis of maximum heart rate by using the Varghese (1994) equation. The physiological parameters of the farm workers for the transplanter and convention methods were shown in table 4 . In conventional methods of transplanting the maximum heart rate recorded was 135 beats $\min ^{-1}$ and in the case of developed transplanter the maximum heart rate was 118 beats $\min ^{-1}$. Based on the maximum heart rate the energy expenditure rate was calculated the value of conventional method is $12.6 \mathrm{KJ} \mathrm{min}{ }^{-1}$ and developed transplanter is $9.8 \quad \mathrm{KJ} \quad \mathrm{min}^{-1}$.Energy expenditure rate was lower in developed transplanter compared with conventional method of transplanting as shown in figure 5.

\section{Oxygen Consumption Rate (OCR)}

The oxygen consumption rate was calculated based on maximum heart rate. The value of conventional method and developed transplanter were $0.859 \mathrm{~L} / \mathrm{min}$ and 0.66 $\mathrm{L} / \mathrm{min}$. Oxygen consumption rate was lower 
in developed transplanter as compared with conventional method of transplanting.

\section{Work pulse value}

The work pulse value of farm farm workers were 30 beats $\min ^{-1}$ and 50.5 beats $\min ^{-1}$ under developed transplanter and convention method of transplanting. In developed transplanter operation, the work pulse value was less as compared to acceptable workload $(30<\mathrm{AWL})$. The conventional method of transplanting, the work pulse rate was high as compared to acceptable workload (50.5 > AWL).

\section{Work load}

The workload was classified as moderate using tow row paper pot onion transplanter and heavy with conventional method of transplanting. Farmers were comfortable while working with the developed transplanter as they were relieved from back pain.

Table.1 Physiological characteristics of farm workers

\begin{tabular}{|c|l|c|}
\hline SI.No & \multicolumn{1}{|c|}{ Particulars } & Average values \\
\hline 1 & Age, years & $29.4 \pm 3.09$ \\
\hline 2 & Weight, $\mathrm{kg}$ & $62.5 \pm 6.46$ \\
\hline 3 & Heart rate at resting posture, beats $\mathrm{min}^{-1}$ & 85 \\
\hline
\end{tabular}

Table.2 Specification of manually operated two row paper pot onion transplanter

\begin{tabular}{|c|l|l|}
\hline SI.No & \multicolumn{1}{|c|}{ Details } & \multicolumn{1}{c|}{ Specification } \\
\hline 1 & Type & $\begin{array}{l}\text { Manually operated twp row paper pot } \\
\text { transplanter }\end{array}$ \\
\hline 2 & Dimension $(\mathrm{L} \times \mathrm{W} \times \mathrm{H}), \mathrm{cm}$ & $157 \times 60 \times 90$ \\
\hline 3 & Weight, $\mathrm{kg}$ & 30 \\
\hline 4 & Planting mechanism & By the gravity force \\
\hline 5 & No. of rows & 2 \\
\hline 6 & Effective width, $\mathrm{cm}$ & 60 \\
\hline 7 & Power source & One person \\
\hline 8 & Seedling tray dimension $(\mathrm{L} \times \mathrm{W} \times \mathrm{H}), \mathrm{cm}$ & 60 \\
\hline 9 & Number of person needed for transplanting & Two (alternate operation and brings seedlings $)$ \\
\hline
\end{tabular}

Table.3 Classification of workload

\begin{tabular}{|l|c|c|}
\hline \multirow{2}{*}{ Physical workload } & \multicolumn{2}{|c|}{ Physiological variables } \\
\cline { 2 - 3 } & Energy Expenditure (KJ/Mi & Heart beats (Beats/Mi \\
\hline Very light & Up to 5.0 & Up to 90 \\
\hline Light & $5.0-7.5$ & $91-105$ \\
\hline Moderate & $7.6-10.0$ & $106-120$ \\
\hline Heavy & $10.0-12.5$ & $121-135$ \\
\hline Very heavy & $12.6-15.0$ & $136-150$ \\
\hline Extremely heavy & $>15.0$ & Above 150 \\
\hline
\end{tabular}


Table.4 Basic anthropometric and physiological parameters of the farm workers- Average values

\begin{tabular}{|c|l|c|c|}
\hline SI.No & \multicolumn{1}{|c|}{ Particulars } & Transplanter & Conventional meth \\
\hline 1 & Resting heart rate, beats $\mathrm{min}^{-1}$ & 85 & 85 \\
\hline 2 & Maximum heart rate, beats $\mathrm{min}^{-1}$ & 118 & 135 \\
\hline 3 & Energy expenditure, $\left(\mathrm{KJ} \mathrm{min}^{-1}\right)$ & 9.8 & 12.6 \\
\hline 4 & Oxygen consumption rate $(\mathrm{L} / \mathrm{min})$ & 0.66 & 0.859 \\
\hline 5 & Work pulse value, beats $\mathrm{min}^{-1}$ & 32 & 50.5 \\
\hline 6 & Work load & Moderate & High \\
\hline
\end{tabular}

Table.5 Overall discomfort rating (ODR), Responses on musculo-skeletal problems and perceived exertion experienced by respondents (RPE)

\begin{tabular}{|c|c|c|c|}
\hline Transplanting methods & ODR & MSP & RPE \\
\hline Transplanter & 5 & Moderate to light pain in hands, shoulder and legs & Moderate \\
\hline Conventional method & 8 & Heavier pain in upper and lower back, hands, legs and fingers & Heavy \\
\hline
\end{tabular}

Fig.1 Isometric view of manually operated two row paper pot onion transplanter
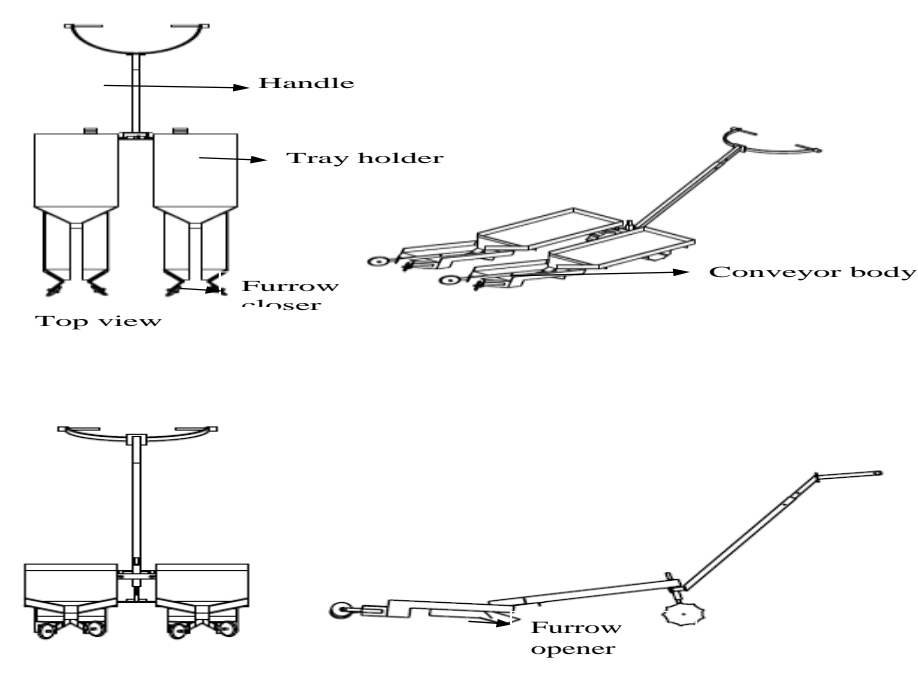

Front view

Side view

Fig.2 Operation of developed transplanter in actual field operation
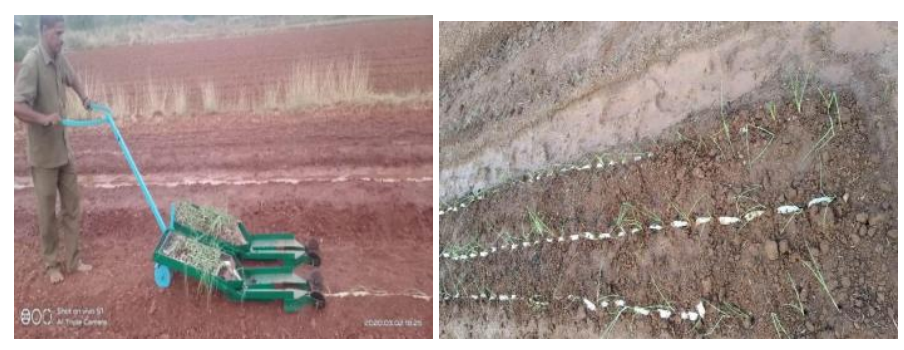
Fig.3 Manual transplanting of onion seedlings

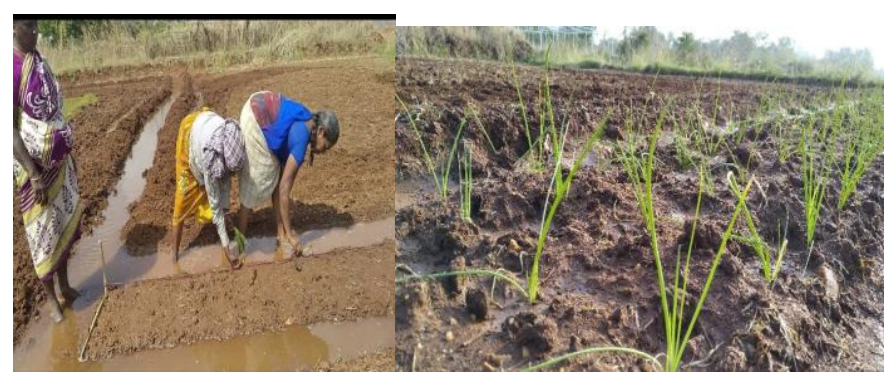

Fig.4 Visual analogue discomfort scale for assessment of overall body discomfort

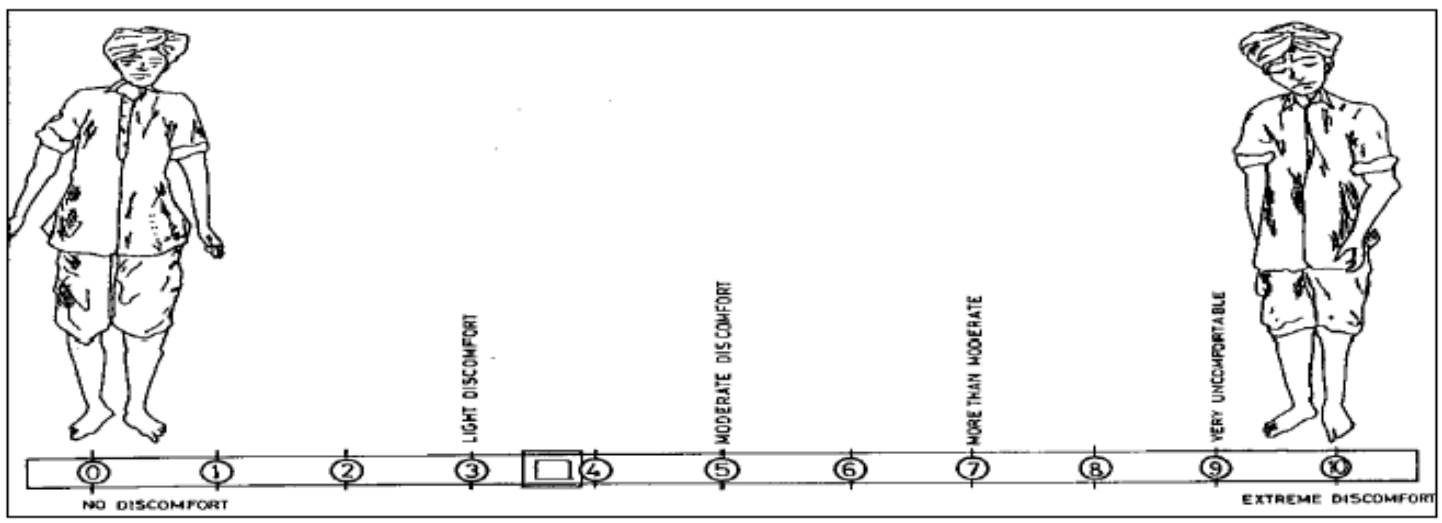

(Corlett and Bishop, 1976)

Fig.5 Comparison of developed transplanter and conventional method of onion transplanting based on heart rate and energy expenditure rate

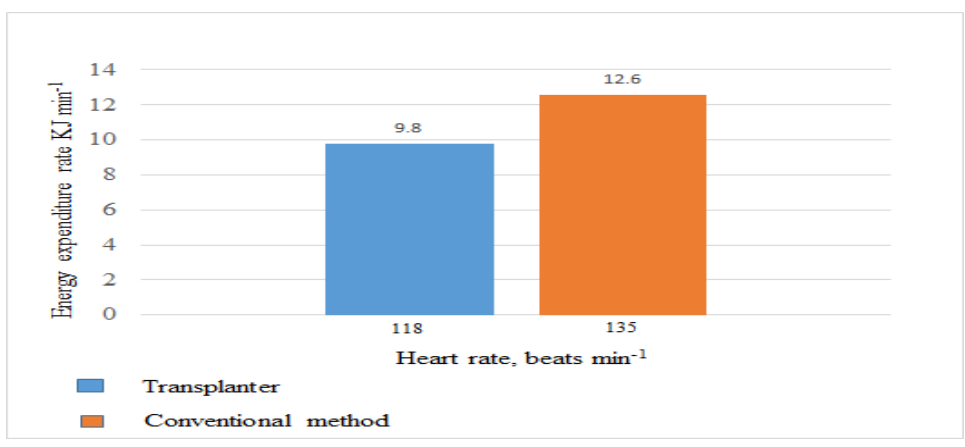

\section{Musculo-skeletal problems (MSP)}

Musculo-skeletal problems and posture were evaluated by asking farm workers as to where they felt pain in their body after transplanting seedlings with a developed transplanter and conventional method. Table 4 indicates that the transplanting with conventional methods makes heavier pain in the upper and lower back, hands, legs and fingers. In the case of two row paper pot transplanter made moderate discomfort and slight pain in hands, shoulder and legs. In transplanter sitting posture was eliminated and also rating of 
perceived exertion as moderate compared with conventional method of transplanting.

\section{Overall discomfort rate}

Musculoskeletal problems are very prominent for transplanting operations because they take more time and are continuous. The conventional methods performed continuous sitting posture which resulted in heavy workload, energy expenditure and in case of two row paper pot transplanter was used in standing posture and thus result in moderate musculo-skeletal problem, energy expenditure rate and workload (Table 5).

In conclusion the manually operated two row paper pot onion transplanter with the selected 10 farm workers were ergonomically evaluated and compared with conventional method of transplanting. The conventional method of transplanting maximum heart rate, oxygen consumption rate, energy expenditure rate, work pulse value and workload was 135 beats $\mathrm{min}^{-1}, 0.859 \mathrm{~L} / \mathrm{min}, 12.6 \mathrm{KJ} \mathrm{min}^{-1}, 32$ beats $\mathrm{min}^{-1}$ and heavy respectively. The corresponding values for the developed transplanter were 118 beats $\mathrm{min}^{-1}, 0.66 \mathrm{~L} / \mathrm{min}$, $12.6 \mathrm{KJ} \mathrm{min}{ }^{-1}, 50.5$ beats $\mathrm{min}^{-1}$ and moderate respectively. The overall discomfort rate was moderate as in developed transplanter and compared with conventional methods of transplanting.

\section{References}

Amita Gautam, Jogdand S.V and Omprabha. 2020. Ergonomic study of farm women for selected agricultural implements. Journal of pharmacognosy and phytochemistry. 9(1): 298-300

Anonymous, 2018. Horticultural statistics at a glance. Government of India Controller of publication. PDES - 256(E) $500-$ 2018 - (DSK - III)

Brudke, J. 1984. Langzeitmes-sungen der
Pulsfrequenz and moglichkeiten der aussage uber die Arbeitsunchungen, Schriftenreihe Arbeiyswissenschaft and Praxis, Band. Berlin: Beuth- Vertrieb.

Choudhury, D., Singh, V. V. and Dubey, A. K. (2001). Refinement and adopting mechanical vegetable transplanters for Indian conditions. Paper presented in 35th Annual Convection of ISAE held at College of Agricultural Engineering and Technology, OUAT, Bhubaneswar (Orissa), India.

Corlet EN, Bishop RP. 1976. A technique for assessing postural discomfort. Ergonomics. 119:175-182

Gite, L.P and Gyanendra Singh. 1997. Ergonomics in agricultural and allied activities in India. Central of Agricultural Engineering.

Pradhan S, Mohanty SK. (2014) ErgoEconomical analysis different paddy transplanting operations in Eastern India. Journal of agriculture and Veterinary Science. 23-27.

Tiwari. P.S. and L. P Gite. 1998. Human energy expenditure during power tiller operations. Paper presented during XXXIII annual convention of ISAE, CIAE, Bhopal, Sept. pp. 21-23.

Tripathi and Neha (2016). Ergonomic evaluation of transplantation activity of vegetable production by traditional and hand operated sapling transplanter (Doctoral dissertation, GB Pant University of Agriculture and Technology, Pantnagar-263145 (Uttarakhand).

Singh, S. P., Gite, L. P., Majumder, J., \& Agarwal, N. (2008). Aerobic capacity of Indian farm women using submaximal exercise technique on treadmill. Agricultural Engineering International: CIGR Journal.

Singh, S. P. 2010. Ergonomical Evaluation of Cono-Weeder with Farm Women. Agricultural engineering today, 34(3), 
31-36..

Singh S.P. 2012. Physiological workload of farm women while evaluating sickles for paddy harvesting

Varghese MA, Saha PN, Atreya N. A 1994. A rapid appraisal of occupational workload from a modified scale of perceived exertion. Ergonomics. 37:485-191.

Vinay Kumar and Neeraj Singh Parihar. 2018. Ergonomic evaluation of manually operated single row vegetable transplanter. Journal of Pharmacognosy and Phytochemistry. 7(3):683-685.

Vyavahare, R. T. and Kallurkar, S. P. 2012. Anthropometric and strength data of Indian agricultural workers for equipment design: a review. Agricultural Engineering International: The CIGR E-journal. 14(4): 102-114.

Yadav R, Patel M, Shukla SP, Pund S. 2007. Ergonomic evaluation of manually operated six-row paddy transplanter. International Agricultural Engineering Journals. 16:147-157.

\section{How to cite this article:}

Suwathiga, M., S. Thambidurai, S. S. Sivakumar and Dhandapani, M. 2020. Ergonomic Evaluation of Manually Operated Two Row Paper Pot Onion Transplanter. Int.J.Curr.Microbiol.App.Sci. 9(11): 2729-2737. doi: https://doi.org/10.20546/ijcmas.2020.911.331 